Article

\title{
Cholesterol-Bearing Fluorescent G-Quadruplex Potassium Probes for Anchoring at the Langmuir Monolayer and Cell Membrane
}

\author{
Angelika Świtalska ${ }^{1, *}$, Anna Dembska ${ }^{1}$, Agnieszka Fedoruk-Wyszomirska ${ }^{2}$ and \\ Bernard Juskowiak 1 (D) \\ 1 Faculty of Chemistry, Adam Mickiewicz University, Umultowska 89b, 61-614 Poznan, Poland; \\ aniojka@amu.edu.pl (A.D.); juskowia@amu.edu.pl (B.J.) \\ 2 Institute of Bioorganic Chemistry, Polish Academy of Sciences, Noskowskiego 12/14, 60-704 Poznan, Poland; \\ agaw@ibch.poznan.pl \\ * Correspondence: switalskaang@gmail.com or angelika.swiatkowska@amu.edu.pl; Tel.: +48-618-291-771
}

Received: 6 June 2018; Accepted: 2 July 2018; Published: 9 July 2018

\begin{abstract}
The purpose of the present work was to design, synthesize and spectrally characterize cholesterol-anchored fluorescent oligonucleotide probes (Ch(F-TBA-T), Ch(py-TBA-py)), based on G-quadruplexes, which were able to incorporate into a lipid structure (Langmuir monolayer, living cell membrane). The probes, based on the thrombin-binding aptamer (TBA) sequence, were labeled with fluorescent dyes which enabled simultaneous monitoring of the formation of G-quadruplex structures and visualization of probe incorporation into the cellular membrane. The combinations of fluorophores used included fluorescence resonance energy transfer (FRET) and excimer emission approaches. The structural changes of the probes upon binding with $\mathrm{K}^{+}$or $\mathrm{Na}^{+}$ions were monitored with fluorescence techniques. These systems showed a very high binding preference for $\mathrm{K}^{+}$over $\mathrm{Na}^{+}$ions. The use of confocal fluorescence microscopy indicated successful anchoring of the cholesterol-bearing fluorescent probes to the living cell membrane. These structurally simple cholesterol-based fluorescent probes have good potential for opening up new and exciting opportunities in the field of biosensors; e.g., in vivo detection of $\mathrm{K}^{+}$ions.
\end{abstract}

Keywords: cholesterol anchor; G-quadruplex; FRET; pyrene; Langmuir monolayer; living cell membrane; potassium sensing

\section{Introduction}

The structure and function of biological membranes are largely controlled by their lipid composition, and particularly by cholesterol, which represents up to $40 \%$ of the lipids in plasma membranes [1,2]. Since the pioneering works of Letsinger [3,4] and Stein [5], a large number of oligonucleotides have been modified with cholesterol to enhance their biological activity [6].

On the other hand, functionally designed lipid-anchored DNA oligonucleotides have significantly promoted many important developments in fields such as nanobiotechnology [7-9], cell biology [9-11], and the development of therapeutic strategies in medicine [12,13]. To precisely control the cellular behaviors in these applications, an improved understanding of the physicochemical properties of cell membranes as well as their interactions with DNA is required. Amphipathic oligonucleotides have been heavily exploited to mimic membrane association processes in natural systems; however, the interactions between biomembranes and G-quadruplexes are very poorly understood. There is much debate about the existence of G-quadruplexes in cells, although G-quadruplexes have recently been detected in human cells using a structure-specific antibody [14]. 
G-quadruplexes are unique higher-order structures formed by G-rich nucleic acid sequences, based on stacked arrays of G-quartets, and connected by Hoogsteen type cyclic hydrogen bonding. Formation of G-quadruplexes requires runs of guanine on one, two or four strands, resulting in linear (four strand), or folded (one or two strand) structures [15]. It is also known that a G-quadruplex has a channel at its center with a diameter that correlates well with the ionic radius of $\mathrm{K}^{+}(1.3 \AA)$ and $\mathrm{Na}^{+}(1.16 \AA)$; hence, physiological buffer conditions favor their formation [16]. In particular, a $\mathrm{K}^{+}$ion can be located in the cavity between two adjacent G-tetrads of a G-quadruplex due to its appropriate size, coordinated by eight carbonyl oxygen atoms from the G-tetrads. The coordination contributes to $\mathrm{K}^{+}$having the highest efficiency among all alkali cations for stabilizing G-quadruplex, which confers the selectivity of some G-quadruplex DNAs for $\mathrm{K}^{+}$[17]. Sensitive and selective detection of $\mathrm{K}^{+}$is essential to biomedical diagnosis. However, it is a challenge to selectively determine the extracellular $\mathrm{K}^{+}$concentration, owing to the presence of the large excess of sodium ions $\left(\mathrm{Na}^{+}\right)$ in physiological conditions. In serum, the normal concentration of $\mathrm{K}^{+}$is $3.5-5.3 \mathrm{mM}$, whereas that of $\mathrm{Na}^{+}$is $135-148 \mathrm{mM}$ [18]. Recently, there have been more and more studies using G-quadruplex DNAs as sensing elements for $\mathrm{K}^{+}$detection. The oligonucleotide-based potassium probes have already been developed in our group, and by others, mainly as sensors for potassium in bulk solution [19-23]. In our group [24], oligonucleotides modified with triethyleneglycol-cholesteryl (TEG-cholesteryl) have been developed.

In this paper, we made use of cholesterol-anchored fluorescent probes (Ch(F-TBA-T), $\mathrm{Ch}$ (py-TBA-py)) based on G-quadruplexes for spontaneous anchoring into the hydrophobic interior of lipid structures (Langmuir monolayer, living cell membrane). Fluorescent oligonucleotide probes have a cholesterol moiety $(\mathrm{Ch})$ attached to the $5^{\prime}$ end of a thrombin-binding aptamer (TBA) sequence via a triethylene glycol (TEG) spacer. Cholesterol-based anchoring molecules are also found in eukaryotic membranes, and these molecules can be incorporated into lipid membranes without disrupting the bilayer structure [25]. The $\mathrm{Ch}(\mathrm{F}-\mathrm{TBA}-\mathrm{T})$ probe was labeled with FAM (carboxyfluorescein) and TAMRA (carboxytetramethylrhodamine) dyes, and the $\mathrm{Ch}$ (py-TBA-py) probe with pyrene groups at both termini. As a reference, we carried out experiments with analogous probes without the cholesterol group (F-TBA-T, py-TBA-py).

We present here the spectral properties and G-quadruplex folding ability of these fluorescent oligonucleotide probes at the Langmuir monolayer interface, which mimics a biomembrane surface. Since biological membranes are difficult to study in vivo, much of our understanding of their complex behavior comes from model surfactant bilayer systems such as the Langmuir monolayer. To mimic cellular membranes we used a cationic DODAB (dimethyldioctadecylammonium bromide) amphiphile. Fluorescence spectra of probes at the air/aqueous subphase interface were recorded using a Langmuir trough and spectrofluorimeter equipped with a fiber optic accessory. We utilized UV, fluorescence and circular dichroism (CD) spectroscopy techniques to monitor the folding and spectral properties of G-quadruplexes formed by the designed probes in bulk solutions. Thermal denaturation experiments were also carried out to evaluate the stability of the G-quadruplexes. Finally, a cell-based study was performed to assess the performance of potassium ion sensing probes in live HeLa cells. We loaded two probes into HeLa cells to evaluate their ability to fold into G-quadruplex structures after anchoring in membrane of living cells.

\section{Experimental Section}

\subsection{Materials}

The oligodeoxyribonucleotide-based probes, (F-TBA-T, py-TBA-py, Ch(F-TBA-T) and Ch(py-TBA-py)) were synthesized by Eurogentec (Liège, Belgium), and purified by reversed phase HPLC. Their identities were confirmed by MALDI-TOF MS. Potassium and sodium binding preferences were carefully tuned by selection of a quadruplex-forming oligonucleotide. To avoid problems with tetraplex polymorphism, we chose the 15-mer oligonucleotide with the sequence 
of d(GGTTGGTGTGGTTGG), known as a thrombin-binding aptamer (TBA) [26]. In order to form a suitably flexible structure with an optimum ability to incorporate into the hydrophobic part of the lipid membrane, and to form G-quadruplex, the oligonucleotide has the cholesterol-anchoring moiety, which is linked to the deoxyribose via a triethyleneglycol (TEG) spacer (Scheme 1A). The py-TBA-py probe is labeled with pyrene groups at the $5^{\prime}$ and $3^{\prime}$ ends. In turn, the Ch(py-TBA-py) probe contains an additional $\mathrm{T}$ base at the $5^{\prime}$ end, and a cholesterol moiety attached to the $5^{\prime}$ end of the oligonucleotide. In the case of probe F-TBA-T, the basic TBA sequence was extended by 4 bases (ATTT) on the $3^{\prime}$ end, which improved performance of the F-TBA-T probe as result of protection from contact quenching caused by the dye-dye interactions [20]. In the Ch(F-TBA-T) probe, the TBA sequence was extended by 4 bases at both $5^{\prime}$ and $3^{\prime}$ ends, TTTA and ATTT, respectively. This probe comprises a cholesterol moiety attached to the $5^{\prime}$ end of the oligonucleotide, TAMRA is attached to the $3^{\prime}$ end, and FAM is placed internally via $\mathrm{dT}$ modification. The primary sequences and names of the fluorescent oligonucleotides are given in Table 1. Concentrations of probes were determined using molar absorptivities at $260 \mathrm{~nm}$, since at this wavelength absorbance is not affected by folding into quadruplex [27]. The contribution of label absorbance at $260 \mathrm{~nm}$ was assumed to be ca. $20 \%$ of the absorbance of long-wavelength bands for the labels [28]. The molar absorptivities for DNA parts were calculated by the nearest-neighbor method, from published values of $E_{260}$ for monomer and dimer DNA [29].

Table 1. Fluorescent oligonucleotide probes used in this study.

\begin{tabular}{cr}
\hline Abbreviation of Probes & Sequence \\
\hline F-TBA-T & 5'FAM-GGT TGG TGT GGT TGG ATT T-TAMRA-3' $^{\prime}$-FA \\
Ch(F-TBA-T) & 5-Ch-(dT FAM)-TTT AGG TTG GTG TGG TTG GAT TT-TAMRA-3' \\
py-TBA-py & $5^{\prime}$-py-GGT TGG TGT GGT TGG-py-3' \\
Ch(py-TBA-py) & $5^{\prime}$-Ch-py-TGG TTG GTG TGG TTG G-py-3' \\
TBA & 5'-TGG TTG GTG TGG TT GG-3' $^{\prime}$ \\
\hline
\end{tabular}

All other reagents were purchased from Sigma Aldrich (St. Louis, MO, USA) and were used as received. Potassium chloride $(\mathrm{KCl})$, sodium chloride $(\mathrm{NaCl})$ and dioctadecyldimethylammonium bromide (DODAB) were of extra pure quality. The buffer used in this work was $10 \mathrm{mM}$ Tris adjusted to ca. $\mathrm{pH} 7.5$ with acetic acid and contained $1 \mathrm{mM}$ EDTA (TAE buffer). High-purity water (Polwater, Kraków, Poland) was used throughout. In studies concerning the Langmuir monolayer, Tris buffer, without EDTA addition, adjusted to required $\mathrm{pH}$ by acetic acid was used (TA buffer).

\subsection{Methods}

\subsubsection{UV-Vis Absorption Studies}

UV-Vis spectra and thermal denaturation profiles were obtained with a Cary 100 UV-Vis spectrophotometer with temperature controlled Peltier accessory (Agilent Technologies, Mulgrave, Australia). Absorption spectra of the oligonucleotide probes were recorded in the spectral range of $200-800 \mathrm{~nm}$ at $25^{\circ} \mathrm{C}$. Thermal denaturation profiles were measured at a heating rate of $1 \mathrm{C} / \mathrm{min}$, with absorbance monitoring at $260 \mathrm{~nm}$ and $295 \mathrm{~nm}$ as a function of temperature. Determination of melting temperatures was carried out using a method similar to that previously published $[27,30]$.

\subsubsection{Fluorescence Spectra}

All measurements were performed on a Cary Eclipse spectrofluorimeter (Agilent Technologies, Mulgrave, Australia) with $5 \mathrm{~nm}$ excitation and emission slits, and were carried out using $0.4 \times 1 \mathrm{~cm}$ quartz cuvettes, containing $1 \mathrm{~mL}$ of sample solution. Fluorescence emission spectra for pyrene-labeled probes were recorded in the 350-650 nm range, with the excitation wavelength of $340 \mathrm{~nm}$. In turn, fluorescence emission spectra for FRET-labeled probes were recorded in the 500-800 nm spectral range, with the excitation wavelength of $490 \mathrm{~nm}$ for FAM and $560 \mathrm{~nm}$ for direct excitation of TAMRA. 
A typical investigation of metal cation effect in the concentration range of $0-0.15 \mathrm{M}$ consisted of successive additions of small portions $(0.1-50 \mu \mathrm{L})$ of a concentrated solution of $3 \mathrm{M} \mathrm{KCl}$ or $3 \mathrm{M} \mathrm{NaCl}$ salt, followed by stirring and thermal equilibration. Studies of the metal cation effect were carried out at $25.0^{\circ} \mathrm{C}$ and $36.6^{\circ} \mathrm{C}$.

FRET efficiency that depended on G-quadruplex formation was evaluated using the ratio of the fluorescence intensity of the TAMRA acceptor excited by $490 \mathrm{~nm}$ to that of the FAM donor: (ratio) $=\mathrm{F}_{583} / \mathrm{F}_{520}$. The monomer/excimer $(\mathrm{m} / \mathrm{e})$ ratio $\left(\mathrm{F}_{490} / \mathrm{F}_{380}\right)$, calculated by comparing the fluorescence intensity of the first monomer peak (typically $\sim 380 \mathrm{~nm}$ ) with that of the excimer band (generally $\sim 490 \mathrm{~nm}$ ), is a relative indicator of the extent of excimer formation, and thus G-quadruplex folding.

\subsubsection{Spectroscopy}

Circular dichroism (CD) measurements were carried out on a Jasco J-820 Spectropolarimeter (Jasco, Tokyo, Japan) equipped with a PTC-423L temperature controller. Spectra were recorded at room temperature approximately $30 \mathrm{~min}$ after sample preparation in $1 \mathrm{~cm}$ path length quartz cells using $1 \mu \mathrm{M}$ solution of a probe in $10 \mathrm{mM}$ TAE buffer ( $\mathrm{pH}$ 7.5) and potassium or sodium salt. A typical investigation of metal cation effect in the concentration range of $0-0.15 \mathrm{M}$ consisted of successive additions of small portions $(0.1-50 \mu \mathrm{L})$ of a concentrated solution of $3 \mathrm{M} \mathrm{KCl}$ or $3 \mathrm{M} \mathrm{NaCl}$ salt, followed by stirring and thermal equilibration. The effect of temperature was evaluated by heating the samples from $10^{\circ} \mathrm{C}$ to $90^{\circ} \mathrm{C}\left(1{ }^{\circ} \mathrm{C} / \mathrm{min}\right)$ and recording the $\mathrm{CD}$ spectra at specific intervals of $5{ }^{\circ} \mathrm{C}$ degrees after thermal equilibrium was attained. The $\mathrm{CD}$ spectra were obtained by taking the average of three scans in the range of $340-220 \mathrm{~nm}$, with a scan rate of $200 \mathrm{~nm} / \mathrm{min}$. The scan of the corresponding buffer solution was subtracted from the average scan for each sample.

\subsubsection{Measurements of $\pi$-A Isotherms and Fluorescence Spectra at the Monolayer Interface}

A computer-controlled film balance system (Langmuir trough small, KSV NIMA, Espoo, Finland) equipped with a platinum Wilhelmy plate pressure sensor was used to obtain the surface pressure-area $(\pi-\mathrm{A})$ isotherms for the DODAB (dimethyldioctadecylammonium bromide) monolayer at the air-water interface, and to maintain required surface pressure of the monolayer upon recording fluorescence spectra of the probes adsorbed at the monolayer interface. The temperature of the subphase was kept at $25.0^{\circ} \mathrm{C} \pm 0.2{ }^{\circ} \mathrm{C}$ by means of a water circulation bath. The monolayer was obtained by spreading the solution of DODAB in chloroform $(1 \mathrm{mM})$ onto a subphase containing buffer and other reagents (fluorescent probes and/or salts) using a microsyringe. Compression experiments started after a 15-min incubation to evaporate the organic solvent. A symmetric compression with a constant barrier speed of $5 \mathrm{~cm}^{2} / \mathrm{min}$ was used. The trough size and volume were $195 \times 50 \mathrm{~mm}$ and $50 \mathrm{~mL}$ respectively.

Fluorescence measurements of monolayer-adsorbed probes were carried out using a system consisting of a Langmuir trough and Cary Eclipse spectrofluorimeter equipped with a fiber optic accessory (Agilent Technologies, Mulgrave, Australia) shown in Scheme S1 in the electronic supplementary information (ESI). The DODAB monolayer was formed on the subphase containing the probe at a strand concentration of $8.3 \mathrm{nM}$ (the charge ratio of the DODAB:probe was 1:1).

Fluorescence emission spectra for pyrene-labeled probes (py-TBA-py, $\mathrm{Ch}(\mathrm{py}-\mathrm{TBA}-\mathrm{py})$ ) were recorded in the 350-650 $\mathrm{nm}$ range, with the excitation wavelength of $330 \mathrm{~nm}$. In turn, fluorescence emission spectra for FRET-labeled probes (F-TBA-T, Ch(F-TBA-T)) were recorded in the 500-800 nm spectral range, with the excitation wavelength of $470 \mathrm{~nm}$ for FAM and $550 \mathrm{~nm}$ for TAMRA. The background spectra were first recorded prior to DODAB spreading, and then after monolayer formation during different experimental conditions. The effect of surface pressure on fluorescence spectra was tested after stepwise compression of the monolayer from $\pi=0$ to $20 \mathrm{mN} / \mathrm{m}$. A 10-min delay followed each compression step to allow relaxation of the monolayer. The fluorescence spectra exhibited reproducible characteristics within at least $60 \mathrm{~min}$ in the compressed state. 
2.2.5. Introduction of the Probe into Membrane of Living Cell for Fluorescence Imaging Experiment

HeLa were seeded at a density of $1.2 \times 10^{5}$ cells per well in 4-chamber glass-bottom cell culture dishes (Grenier Bio-One, Kremsmünster, Austria) and cultured in RPMI 1640 antibiotic-free medium (Sigma, Kawasaki, Japan) supplemented with 10\% ( $v / v)$ fetal bovine serum (FBS) (Gibco), and 1\% RPMI 1640 vitamin solution (Sigma, Kawasaki, Japan) at $37^{\circ} \mathrm{C}$ under a $5 \% \mathrm{CO}_{2}$ atmosphere. After one day, the cells reached the appropriate density (80-90\% confluence) and were placed in fresh RPMI 1640 medium without supplements. Then the $\mathrm{Ch}(\mathrm{F}-\mathrm{TBA}-\mathrm{T})$ probe was added to the culture medium to obtain the final concentration, $50 \mathrm{nM}$ or $200 \mathrm{nM}$. The visualizations were done after $24 \mathrm{~h}$ of treatment. The three other sample sets with $\mathrm{Ch}(\mathrm{F}-\mathrm{TBA}-\mathrm{T})(50 \mathrm{nM})$ were prepared $3.5 \mathrm{~h}, 2.0 \mathrm{~h}$ and $30 \mathrm{~min}$. before visualization. The positive control was HeLa cells treated with the F-TBA-T probe ( $50 \mathrm{nM}$ ) added to the culture medium $24 \mathrm{~h}$ before visualization. The negative control was untreated cells. Before fluorescence confocal microscopy analysis, cells were washed twice with phosphate buffered saline (PBS) and placed in FluoroBright Live Cell Fluorescence Imaging Medium. In experiments using Hoechst 33342 (Sigma, Kawasaki, Japan), the dye was applied to medium in a final concentration of $5 \mu \mathrm{g} / \mathrm{mL}$ and images were taken after $15 \mathrm{~min}$.

\subsubsection{Fluorescence Imaging Experiments}

Imaging was carried out with a confocal laser fluorescence inverted microscope using a Spectral Confocal Microscopy TCS SP5 II Leica system equipped with a white light laser (470-670 nm) and a 405 laser, and an environmental cell culture chamber that provided controlled conditions of temperature, $\mathrm{CO}_{2}$ saturation and humidity. Sequentially scanned live-cell images were collected using a Plan Apo $63 \times 1.4$ NA oil-immersion objective. Leica LAS AF SP software was used for control of image processing and fluorescence analysis. The fluorescence imaging was taken using excitation/emission (ex/em) wavelengths as follows:

(a) FAM (fluorescein) channel, ex $/$ em range $=480 / 510-540 \mathrm{~nm}$.

(b) TAMRA channel, ex $/$ em range $=560 / 595-630 \mathrm{~nm}$.

(c) FRET channel, ex $/$ em range $=480 / 595-630 \mathrm{~nm}$.

(d) Hoechst channel, ex/em range $=405 / 480-500 \mathrm{~nm}$.

\section{Results and Discussion}

\subsection{Design and Working Principle of Cholesterol-Anchored Fluorescent Oligonucleotide Probes}

The model cholesterol-anchored fluorescent oligonucleotide probes for potassium sensing at the cell membrane interface are illustrated in Scheme 1. The amphiphilic lipid-DNA probe consists of a hydrophobic cholesterol moiety, hydrophilic DNA strand, and fluorophores attached to DNA (Scheme 1A). The Ch(F-TBA-T) probe was modified with FAM and TAMRA, whereas the $\mathrm{Ch}$ (py-TBA-py) probe was modified with pyrene groups, at the $5^{\prime}$ - and $3^{\prime}$-termini of the oligonucleotide, respectively. Due to the phospholipid bilayer structure of the cell membrane, lipid-DNA probes can be directly anchored on the membrane through the hydrophobic interaction between the cholesterol moiety and the phospholipid. Thus, anchoring DNA makes use of the naturally occurring membrane constituent, consequently eliminating the risk of side effects induced by chemically reactive lipid headgroups incorporated in membrane constituents [25]. 
(A)
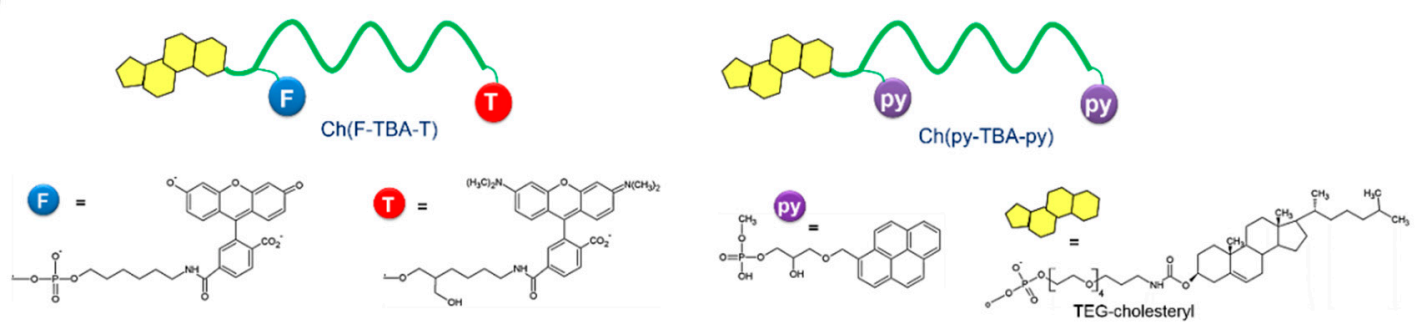

(B)
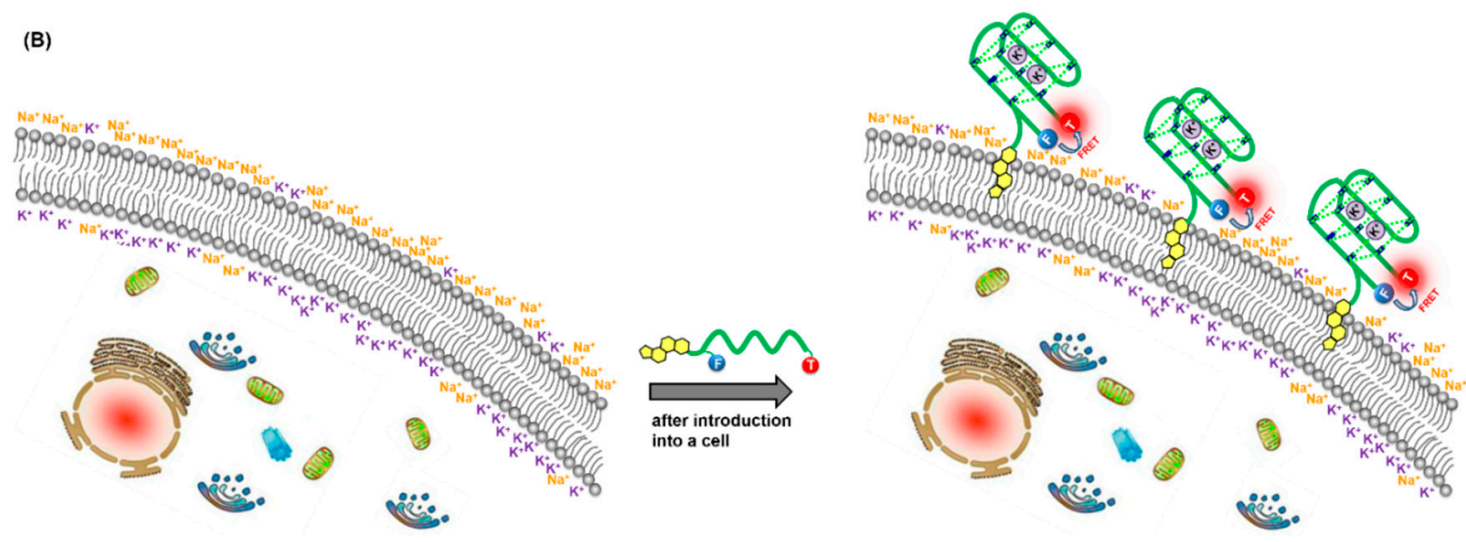

Scheme 1. Structure of the cholesterol-anchored fluorescent probes (A), working principle of cell-anchored cholesterol-fluorescent probes (B).

Intramolecular folding of a flexible single-stranded DNA molecule into a compact G-quadruplex leads to closer proximity of its $5^{\prime}$ and $3^{\prime}$ ends. Thus, labeling both ends of the DNA strand with suitable fluorophores enables monitoring of the quadruplex-formation process as result of the fluorescent signal generation. In our research, we use two types of fluorescent approaches: (i) based on the fluorescence resonance energy transfer (FRET); and (ii), switching of monomer-excimer emission of pyrene fluorophores. FRET between two molecules is an important physical phenomenon, where transfer of energy occurs from an excited donor fluorophore to a suitable acceptor fluorophore. The basic requirements for the FRET to occur are: (i) sufficient overlap between the absorption band of acceptor and the fluorescence band of donor; and (ii), both the donor and the acceptor molecule must be in close proximity, in the order of 1-10 nm. The interference of solvent or other macromolecules has little effect on FRET efficiency [31,32]. The advantages of the pyrene probes are the high Stokes shift between monomer and excimer emission, and their relatively long lifetime (30-60 ns) compared to the lifetime of the autofluorescence background (about $8 \mathrm{~ns}$ ) [32-34].

In the first strategy, an oligonucleotide-bearing thrombin binding aptamer sequence was end-labeled with fluorescent groups (FAM and TAMRA) to give FRET probe- Ch(F-TBA-T). The Ch(F-TBA-T) probe additionally has a cholesterol anchor at the $5^{\prime}$ end. FAM and TAMRA dyes were chosen as donor and acceptor, respectively. The probe exhibited the ability to fold into the quadruplex structure and to bind metal cations $\left(\mathrm{Na}^{+}\right.$and $\left.\mathrm{K}^{+}\right)$. As shown in Scheme $1 \mathrm{~B}$, before anchoring into membrane (in an unbound state), $\mathrm{Ch}$ (F-TBA-T) possesses spatially separated termini and exhibits an unperturbed fluorescence spectrum dominated by FAM (donor) emission. Upon incorporation into the membrane, and in the presence of $\mathrm{K}^{+}\left(\mathrm{Na}^{+}\right)$ion, the quadruplex structure is developed that enables fluorophores to be arranged in close proximity causing alteration of their fluorescence spectra (quenching of the FAM band and enhancement of the TAMRA emission).

The second type of probe (Ch(py-TBA-py)) also possesses cholesterol moiety and can be anchored into the cell membrane but uses the pyrene excimer emission for the transduction of the cation-binding event. After G-quadruplex structure formation, in which two pyrenes are located in close proximity, 
an excimer emission can appear. This excimer exhibits a broad red-shifted emission band near $480 \mathrm{~nm}$, in contrast with the structured emission of the pyrene monomer at 380 and $400 \mathrm{~nm}$.

Two reference probes were also designed, which lacked the cholesterol anchor but preserved other structural components (TBA recognition oligonucleotide and pyrene or FRET labels).

\subsection{Spectral Properties of the Fluorescent Probes in Solution}

The spectral properties of fluorescent oligonucleotides were first investigated in buffer solution in order to verify their abilities to generate fluorescence signal upon G-quadruplex formation. All probes were tested in sample solutions containing metal cations at concentrations corresponding to the intraand extra- cellular conditions.

The FRET-probes (F-TBA-T, Ch(F-TBA-T)) exhibited absorption bands at $260 \mathrm{~nm}, 494 \mathrm{~nm}$, and $560 \mathrm{~nm}$ (Figure S1A,B ESI), and the pyrene-labeled probes (py-TBA-py, Ch(py-TBA-py)) exhibited absorption bands at $260 \mathrm{~nm}, 326 \mathrm{~nm}$, and $340 \mathrm{~nm}$ (Figure S1C,D, ESI), as expected for dual-labeled oligonucleotides with FAM-TAMRA and py-py labels, respectively. The long-wavelength absorption bands are characteristic of FAM and TAMRA ( $494 \mathrm{~nm}$ and $560 \mathrm{~nm}$, respectively) and pyrene groups $(325 \mathrm{~nm}, 340 \mathrm{~nm})$, but the band at $260 \mathrm{~nm}$ should be ascribed mainly to the absorption of nucleobases. It should be noted that very similar spectra were obtained for all probes studied in the absence as well as presence of $\mathrm{K}^{+}$and $\mathrm{Na}^{+}$ions, irrespective of whether they contained cholesterol moiety or not. This is not surprising since cholesterol has a low molar absorption band at $260 \mathrm{~nm}(\varepsilon \sim 100$ [35]).

Thermal stability and kinetics of G-quadruplex folding for cholesterol-containing fluorescent probes were evaluated in the presence of $\mathrm{K}^{+}(100 \mathrm{mM})$ or $\mathrm{Na}^{+}(100 \mathrm{mM})$ ions using the denaturation profiles recorded with absorbance at $295 \mathrm{~nm}$. The obtained melting profiles are shown in Figure S2, ESI. Temperatures at half transition for the all probes in the presence of $\mathrm{K}^{+}$and $\mathrm{Na}^{+}$ions can be found in Table 2. The literature reports melting temperatures of TBA in the presence of $\mathrm{Na}^{+}$and $\mathrm{K}^{+}$of $24.0^{\circ} \mathrm{C}$ and $53.0^{\circ} \mathrm{C}$, respectively [36,37]. The attached pyrene moieties to the $5^{\prime}$ and $3^{\prime}$ ends of the py-TBA-py probe did not significantly affect the melting temperature $\left(55.0^{\circ} \mathrm{C}\right)$. However, the attachment of FAM/TAMRA dyes, and the increase in the length of the oligonucleotide chain (ATTT spacer), significantly affected the $\mathrm{Tm}$ in the case of the F-TBA-T/ $\mathrm{K}^{+}$complex. The melting temperature for F-TBA- $/ \mathrm{K}^{+}$dropped to $38.0^{\circ} \mathrm{C}$. Interestingly, melting temperatures for the F-TBA-T/Na ${ }^{+}$and py-TBA-py $/ \mathrm{Na}^{+}$systems were almost unaltered compared with that for TBA.

Table 2. Melting temperatures (Tm) for quadruplex-forming oligonucleotide probes determined from dependences of absorbance at $295 \mathrm{~nm}$ in the presence $\mathrm{K}^{+}$and $\mathrm{Na}^{+}$ions.

\begin{tabular}{ccc}
\hline Abbreviation of Probes & $\mathbf{T m} / \mathbf{K}^{+}\left({ }^{\circ} \mathbf{C}\right)$ & $\mathbf{T m} / \mathbf{N a}^{+}\left({ }^{\circ} \mathbf{C}\right)$ \\
\hline F-TBA-T & 38.0 & 23.0 \\
Ch(F-TBA-T) & 48.0 & 39.0 \\
py-TBA-py & 55.0 & 25.0 \\
Ch(py-TBA-py) & 77.0 & 43.0 \\
TBA & 53.0 & 24.0 \\
\hline
\end{tabular}

A possible explanation of lower $\mathrm{Tm}$ for the F-TBA-T $/ \mathrm{K}^{+}$system may involve the more hydrophilic character of this G-quadruplex compared with the native TBA. Both the dye groups and the four-nucleotide spacer introduce additional charges to the probe molecule. Mergny et al. [38] studied the effect of the nucleobase spacer on the stability of tetraplex structures of G-rich oligonucleotides. They showed that an increase in the number of nucleotides in the spacer led to the decrease in thermal stability of the tetraplex structure, which concurs with our observations. It should be noted that the presence of cholesterol moiety, which increases the hydrophobic character of probes, significantly stabilized the G-quadruplexes (Table 2).

The fluorescence spectra of the Ch(F-TBA-T) probe, and its analogue without cholesterol (F-TBA-T), in the presence of $\mathrm{K}^{+}$ion $(0-150 \mathrm{mM})$ are shown in Figures $1 \mathrm{~A}$ and S3A, ESI, respectively. 
Spectra related to $\mathrm{Ch}(\mathrm{F}-\mathrm{TBA}-\mathrm{T}) / \mathrm{Na}^{+}$and F-TBA-T/Na ${ }^{+}$are shown in Figures $1 \mathrm{~B}$ and S3B, ESI, respectively. The fluorescence band observed at $\lambda_{\mathrm{em}}=520 \mathrm{~nm}$ is characteristic of the FAM emission and the band at $\lambda_{\mathrm{em}}=583 \mathrm{~nm}$ is typical for the TAMRA fluorophore. In the unfolded form of both probes (no metal cations), little FRET is expected since the average distance between the donor and the acceptor (ca. $80 \AA$ ) exceeds the critical radius (ca. $50 \AA$ ). Folding of the probe into G-quadruplex with increasing concentration of cations brings these two fluorophores close enough for energy transfer to be efficient. For both probes an increase in $\mathrm{K}^{+}$ion concentration $(0 \rightarrow 150 \mathrm{mM})$ caused considerable quenching of the FAM emission band at $\lambda_{\mathrm{em}}=520 \mathrm{~nm}$ whereas the intensity of the TAMRA band $\lambda_{\mathrm{em}}=583 \mathrm{~nm}$ slightly increased (Ch(F-TBA-T), Figure 1A) or decreased (F-TBA-T, Figure S3A, ESI). It should be noted that the FAM and TAMRA fluorescence bands for the F-TBA-T probe (Figure S3A,B, black line, ESI) possess comparable intensity in the absence of metal ions. The relative high intensity of TAMRA emission in the extended form (no $\mathrm{K}^{+}$ion) of the F-TBA-T probe suggested that this probe might have a shrunken conformation (less than $60 \AA$ rather than its extended one), although the direct excitation of TAMRA acceptor could not be neglected. In turn, the extension of the Ch(F-TBA-T) probe (four bases) changes the donor-acceptor distance, which affects the FRET efficiency. In the absence of $\mathrm{K}^{+}$, fluorescence intensity of the FAM emission band increases, while the relative fluorescence intensity of TAMRA band decreases (Figure 1A). Contrary to potassium, sodium ions exert a much smaller effect on the fluorescence spectra of the probes. Folding of the G-quartet oligonucleotides in the presence of sodium ions was visible only at $50 \mathrm{mM}$ for the $\mathrm{Na}^{+}$ion but at $1 \mathrm{mM}$ in the case of $\mathrm{K}^{+}$ion. It should be pointed out that upon direct excitation at $560 \mathrm{~nm}$, all probes exhibited a substantial decrease in TAMRA fluorescence with an increase in cation concentration (Figure S4, ESI). Some of the spectral properties for the F-TBA-T and Ch(F-TBA-T) probes have been described elsewhere [39].
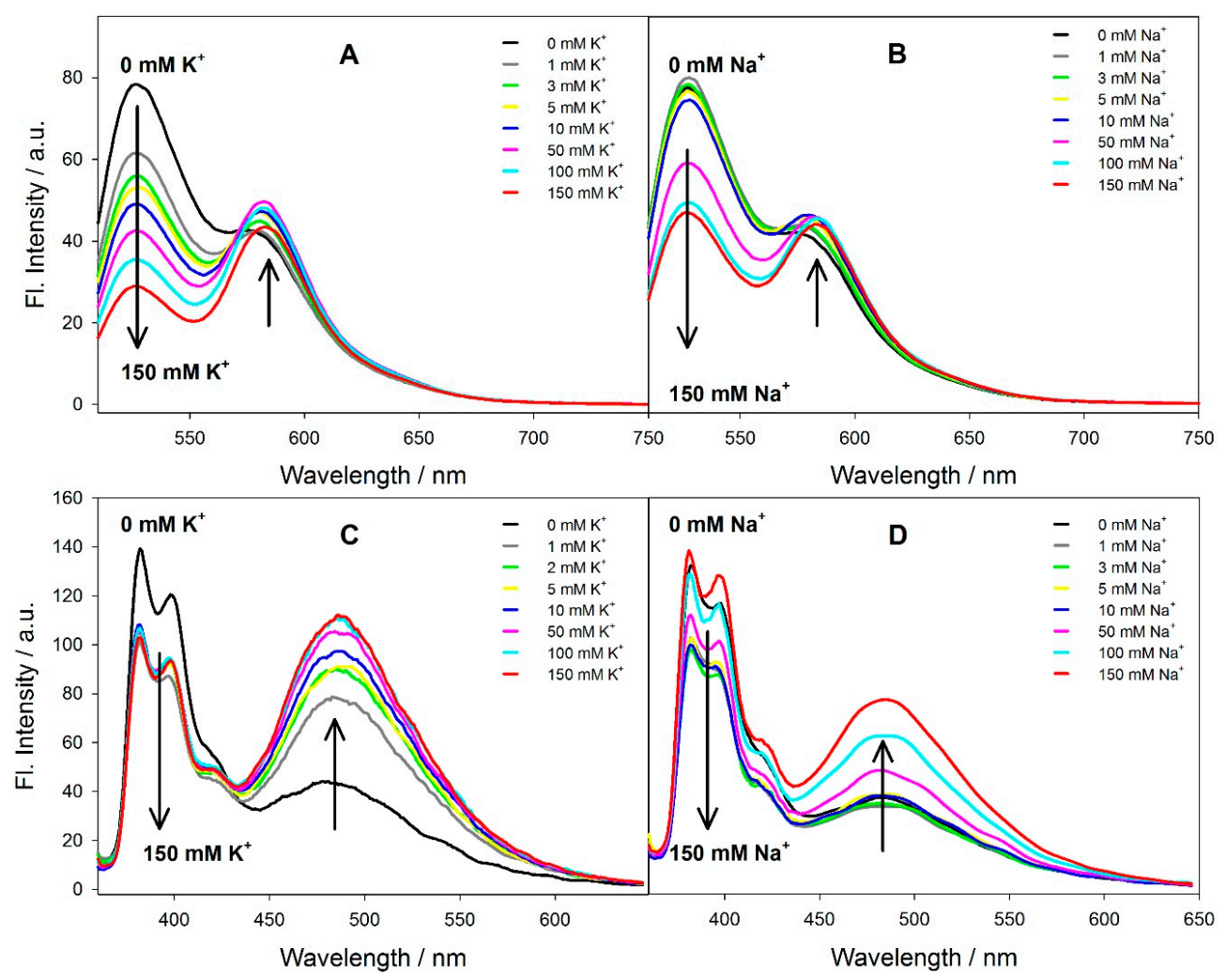

Figure 1. Potassium and sodium ions effect on the fluorescence spectra of $0.2 \mu \mathrm{M} \mathrm{Ch}(\mathrm{F}-\mathrm{TBA}-\mathrm{T})$ ((A,B), respectively) with $\lambda_{\mathrm{ex}}=490 \mathrm{~nm}$, and Ch(py-TBA-py) $\left((\mathbf{C}, \mathbf{D})\right.$, respectively) with $\lambda_{\mathrm{ex}}=340 \mathrm{~nm}$. Conditions: $10 \mathrm{mM}$ TEA buffer (pH 7.5), $\mathrm{KCl}$ and $\mathrm{NaCl}$ concentration: 1, 3, 5, 10, 50, 100, $150 \mathrm{mM}$. 
Figure 2A shows variation of the FRET efficiency expressed as a fluorescence intensity ratio $\left(\mathrm{F}_{583} / \mathrm{F}_{520}\right)$ for $\mathrm{Ch}(\mathrm{F}-\mathrm{TBA}-\mathrm{T})$ plotted against the concentration of $\mathrm{K}^{+}$(blue symbols) and $\mathrm{Na}^{+}$ (red symbols) at $25.0^{\circ} \mathrm{C}$ (circles) and $36.6{ }^{\circ} \mathrm{C}$ (triangles). The fluorescence intensity ratio $\left(\mathrm{F}_{583} / \mathrm{F}_{520}\right)$ of F-TBA-T (probe without cholesterol moiety) is shown in Figure S5A, ESI. For both temperatures, an increase in the FRET signal was observed in the range of $1-10 \mathrm{mM}$ for $\mathrm{K}^{+}$and in the range of 10-150 mM for $\mathrm{Na}^{+}$ions, which is consistent with the TBA binding affinities of these cations. The values of the fluorescence ratio $\left(\mathrm{F}_{583} / \mathrm{F}_{520}\right)$ for F-TBA-T are larger than those for Ch(F-TBA-T) (compare Figures 2A and S5A, ESI). This is reasonable when considering that two dyes in the F-TBA-T probe should be closer, since the length of a 19-meric TBA is $80 \AA$. However, titration with sodium and potassium cations at $36.6{ }^{\circ} \mathrm{C}$ decreased the FRET signal by ca. $50 \%$ in both cases. Moreover, $\mathrm{Ch}(\mathrm{F}-\mathrm{TBA}-\mathrm{T})$ also exhibited good binding selectivity for the $\mathrm{K}^{+}$over the $\mathrm{Na}^{+}$ion, both at $25.0^{\circ} \mathrm{C}$ and at $36.6^{\circ} \mathrm{C}$ (Figure 2A). The F-TBA-T probe exhibited similar spectral changes (Figure S5A, ESI). A plateau region was observed for most plots at higher cation concentrations.
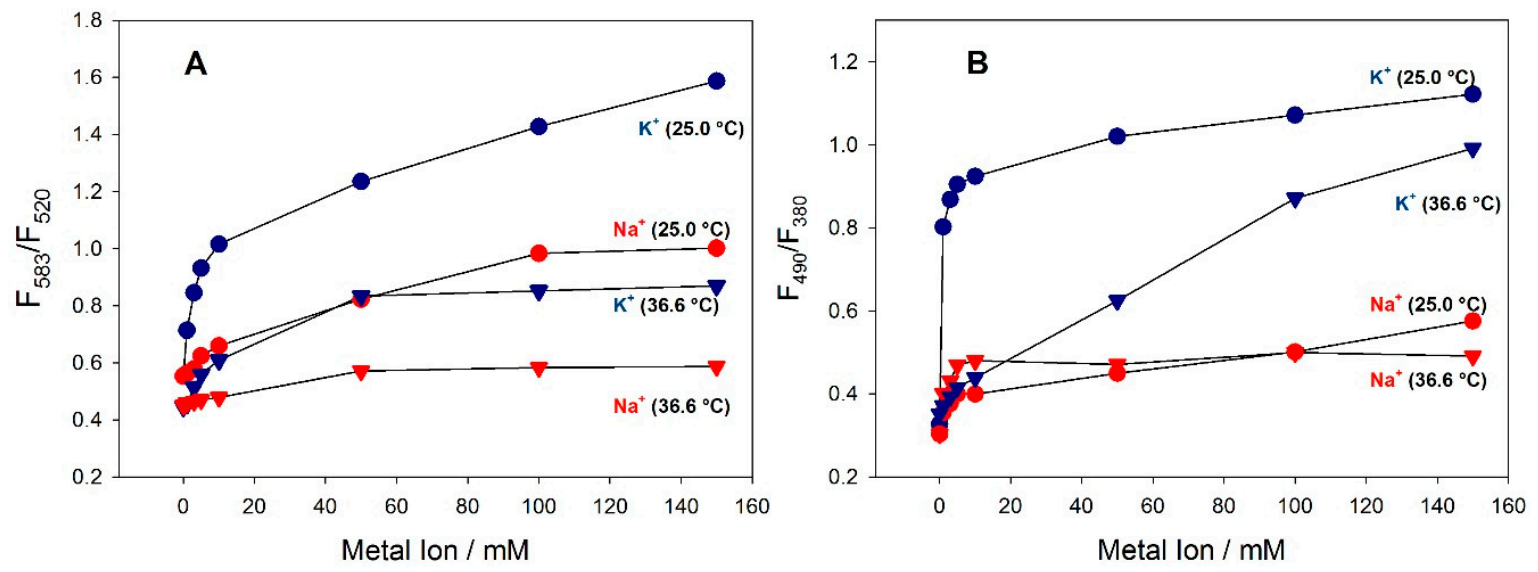

Figure 2. Fluorescence intensity ratio of $\mathrm{Ch}(\mathrm{F}-\mathrm{TBA}-\mathrm{T})\left(\mathrm{F}_{583} / \mathrm{F}_{520}\right)(\mathrm{A})$ and $\mathrm{Ch}(\mathrm{py}-\mathrm{TBA}-\mathrm{py})\left(\mathrm{F}_{490} / \mathrm{F}_{380}\right)$ (B) systems plotted against $\mathrm{K}^{+}$or $\mathrm{Na}^{+}$concentration at $25^{\circ} \mathrm{C}$ and $36.6{ }^{\circ} \mathrm{C}$.

The difficulty in the monitoring $\mathrm{K}^{+}$level in extracellular conditions comes from the coexistence of an excess of sodium ions $\left(\mathrm{Na}^{+}\right.$), thus small variations in $\mathrm{K}^{+}$concentration (around $5 \mathrm{mM} \mathrm{K}$ ) should be monitored in the presence of $140 \mathrm{mM} \mathrm{Na}{ }^{+}$concentration. Because of the high content of $\mathrm{Na}^{+}$, the efficient formation of potassium-quadruplex complex requires significant binding preferences for $\mathrm{K}^{+}$over $\mathrm{Na}^{+}$. Figure S6, ESI shows the fluorescence spectra of Ch(F-TBA-T) in the presence of $150 \mathrm{mM} \mathrm{Na}^{+}$titrated with $\mathrm{K}^{+}$ions in the $1-20 \mathrm{mM}$ concentration range at $25.0^{\circ} \mathrm{C}$ (Figure S6A, ESI) and $36.6{ }^{\circ} \mathrm{C}$ (Figure S6B, ESI). Figure S7, ESI shows the potassium calibration graphs plotted with a ratio of $\mathrm{F}_{583} / \mathrm{F}_{520}$ ) under the same conditions. The probe showed a dynamic range for $\mathrm{K}^{+}$detection of 2-10 $\mathrm{mM}$ in the presence of $150 \mathrm{mM} \mathrm{Na}^{+}$, which is a clinically important concentration region of $\mathrm{K}^{+}$ under an extracellular conditions.

Development of a second type of fluorescent probe exploited the pyrene excimer emission for the transduction of the cation-binding event. The fluorescence spectra of Ch(py-TBA-py) and py-TBA-py $\left(\lambda_{\text {ex }}=380 \mathrm{~nm}\right)$ in the presence of $\mathrm{K}^{+}(0-150 \mathrm{mM})$ are shown in Figures $1 \mathrm{C}$ and S3C, ESI respectively; and those in the presence of $\mathrm{Na}^{+}$ion (0-150 mM) are shown in Figures 1D and S3D, ESI, respectively. A typical excimer emission characteristic of pyrene with a broadband at ca. $490 \mathrm{~nm}$ is observed for both probes in the presence of $\mathrm{K}^{+}$ions, and only for the $\mathrm{Ch}(\mathrm{py}-\mathrm{TBA}-\mathrm{py})$ probe in the presence of $\mathrm{Na}^{+}$. Contrary to potassium, sodium ions exerted much smaller effect on the fluorescence spectrum of the py-TBA-py probe. Folding of the py-TBA-py in the presence of $\mathrm{Na}^{+}$ions only led to quenching of pyrene monomer emission, without the concomitant increase in excimer emission at longer wavelengths. It should be noted that the fluorescence spectra of both Ch(py-TBA-py) and py-TBA-py probes in the absence of metal ions exhibit monomer bands with defined peaks at $380 \mathrm{~nm}$ and $400 \mathrm{~nm}$, 
and a weak shoulder at $490 \mathrm{~nm}$. The weak band at $490 \mathrm{~nm}$ proves that the pyrene moieties interact with each other when probes are in a random coil conformation [33]. The potassium ion gave a positive response at just $1 \mathrm{mM}$, and the sodium ion gave detectable excimer emission for concentrations of $\mathrm{Na}^{+}$ ions exceeding $50 \mathrm{mM}$, which is consistent with the results for FRET-labeled probes.

The monomer/excimer $(\mathrm{m} / \mathrm{e})$ ratio, calculated by comparing the fluorescence intensity (or quantum yield) of the first monomer peak (typically $380 \mathrm{~nm}$ ) with the excimer band (generally $\sim 490 \mathrm{~nm}$ ), is a relative indication of the extent of excimer formation, and therefore a measure of spatial proximity between two pyrene moieties. Figure $2 \mathrm{~B}$ shows the variation of the excimer formation efficiency $\left(\mathrm{F}_{490} / \mathrm{F}_{380}\right)$ for $\mathrm{Ch}$ (py-TBA-py) plotted against the concentration of $\mathrm{K}^{+}$(blue symbols) and $\mathrm{Na}^{+}$(red symbols) at $25.0^{\circ} \mathrm{C}$ (circles) and $36.6^{\circ} \mathrm{C}$ (triangles). Appropriate plots for py-TBA-py (probe without cholesterol moiety) are shown in Figure S5B, ESI. Comparison of the profiles of all plots for py-TBA-py and Ch(py-TBA-py) indicates that: (i) potassium is more effective and produces excimer signal at lower concentration than sodium ion; (ii) the excimer formation efficiency finally attained is higher for $\mathrm{K}^{+}$than for $\mathrm{Na}^{+}$; and (iii), the $\mathrm{F}_{490} / \mathrm{F}_{380}$ ratio is slightly smaller at $36.6{ }^{\circ} \mathrm{C}$ than at $25.0^{\circ} \mathrm{C}$. One should remember, however, that additional factors may affect fluorescence signal; for example, quenching/dequenching processes of FAM and TAMRA fluorophores, pyrene/DNA interactions and presence of a cholesterol group may operate upon the folding of oligonucleotide, and such phenomena also affect the FRET and excimer signals.

More detailed studies on G-quadruplex formation with cholesterol-bearing fluorescent probes were carried out using CD spectroscopy. A thrombin-binding aptamer (TBA) used in this study (Table 1) is known to form only a chair-type anti-parallel intramolecular G-quadruplex structure in the presence of metal cations [40], and such quadruplex formation is readily identified through the positive bands around $295 \mathrm{~nm}$ and $240 \mathrm{~nm}$, and the negative band around $270 \mathrm{~nm}$ in the CD spectrum. Among the various monovalent cations, potassium ions stabilize the TBA quadruplex the most effectively; consequently, the CD spectrum of the TBA-potassium complex exhibits greater band intensities compared with those of other TBA-cation complexes, for example, $\mathrm{Na}^{+}$[41]. The representative $\mathrm{CD}$ spectra for $\mathrm{Ch}$ (F-TBA-T) and $\mathrm{Ch}$ (py-TBA-py) titrated with $\mathrm{KCl}$ and $\mathrm{NaCl}(0-150 \mathrm{mM})$ are shown in Figure 3A-D, respectively. CD spectra for the reference probes without cholesterol moiety (F-TBA-T, py-TBA-py) in the same environmental conditions are shown in Figure S8, ESI. Weak CD peaks are observed for both probes in the absence of $\mathrm{KCl}$, whereas the addition of salt (1-150 $\mathrm{mM})$ causes an appearance of the characteristic G-quadruplex signature-a negative band at 265 and positive bands at 240 and $295 \mathrm{~nm}$ (Figure 3A,C), similar to that observed for the F-TBA-T/K ${ }^{+}$and py-TBA-py/K ${ }^{+}$ complexes without cholesterol moiety (Figure S8A,C, ESI). The intensity of the CD bands rises as the salt concentration increases up to $10 \mathrm{mM} \mathrm{KCl}$. Further addition of salt causes only minor effects on the CD spectra of both probes, indicating that $10 \mathrm{mM}$ concentration of $\mathrm{KCl}$ is sufficient for nearly complete probe formation of quadruplex structures.. CD spectra recorded for all probes (Figures 3B,D and S8B,D, ESI) showed less pronounced spectral changes upon the addition of $\mathrm{Na}^{+}$ions $(0-150 \mathrm{mM})$. A structural change from a random coil to a chair-type quadruplex structure (the negative band near $265 \mathrm{~nm}$ and the positive band at $290 \mathrm{~nm}$ ) was detectable for concentrations of $\mathrm{Na}^{+}$ions exceeding $100 \mathrm{mM}$. The presence of $\mathrm{Na}^{+}$cations causes small changes in the CD spectra because TBA forms a weak complex with $\mathrm{Na}^{+}$ions as a consequence of the difference in binding mode between potassium and sodium ions, in accordance with data in the literature [41]. 

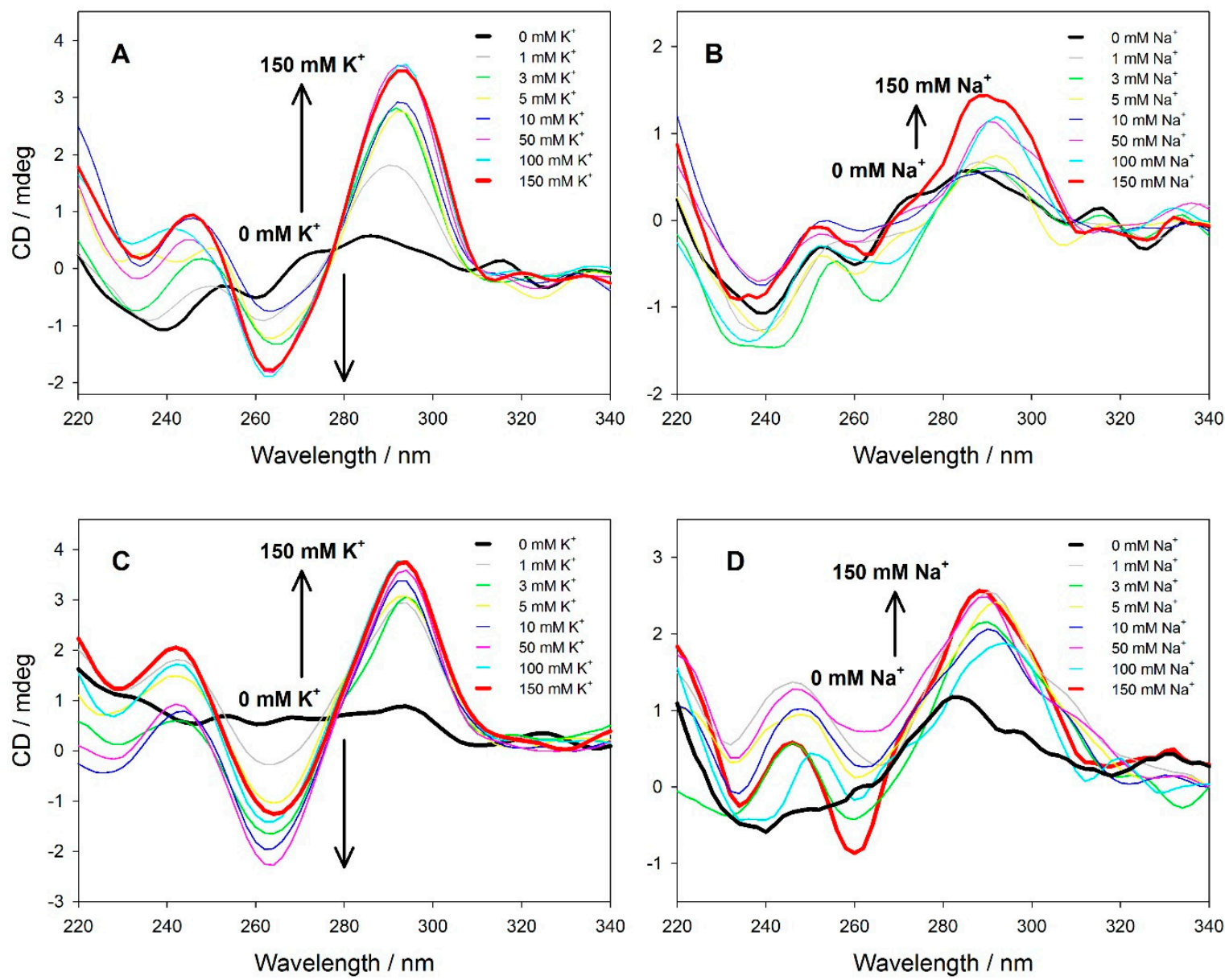

Figure 3. Effect of potassium and sodium ions on the CD spectra of $1 \mu \mathrm{M} \mathrm{Ch}(\mathrm{F}-\mathrm{TBA}-\mathrm{T})(\mathbf{A}, \mathbf{B})$ and Ch(py-TBA-py) (C,D) probes. Conditions: $10 \mathrm{mM}$ TEA buffer ( $\mathrm{pH} 7.5), \mathrm{KCl}$ and $\mathrm{NaCl}$ concentration: $1,3,5,10,50,100,150 \mathrm{mM}$.

This result suggested that all probes underwent a conformational change in the presence of $\mathrm{K}^{+}$ and $\mathrm{Na}^{+}$to an intramolecular tetraplex from the random structure. However, the CD intensity of the $\mathrm{K}^{+}$induced G-quadruplex is much higher than that induced by the sodium ion. The CD patterns for cholesterol-anchored fluorescent probes are very similar to those observed for probes without the cholesteryl group. All these data suggest that attachment of the FAM/TAMRA labels, pyrene groups and cholesterol anchor have negligible effect on the folding properties of TBA oligonucleotide.

\subsection{Fluorescent Probes at the Water/Monolayer Interface}

To demonstrate the feasibility of using cholesterol-containing fluorescent oligonucleotide probes for potassium sensing in living cells, we have carried out preliminary experiments with a Langmuir monolayer of DODAB. The cholesterol-linked probes were soluble in all physiologically relevant solutions and could interact with the Langmuir monolayer via hydrophobic interaction between the cholesterol moiety and the membrane, or via electrostatic interaction between the positively charged DODAB head groups and the negatively charged phosphate groups of DNA.

Oligonucleotides possess negative charges and, being linear, polyelectrolytes can undergo adsorption on the monolayer of cationic surfactants at the air/water interface due to electrostatic attraction forces [42-47]. Our earlier surface pressure-area study showed that interactions of the unlabeled G4 DNA oligonucleotide did not occur with the zwitterionic DPPC (dipalmitoylphosphatidylcholine) monolayer but the $\pi$-A isotherm of the cationic Langmuir film (DODAB) shifted to lower molecular areas in the presence of G4 DNA, indicating electrostatic 
interactions between these two components. However, probes equipped with the cholesterol anchor are expected to incorporate into the monolayer due to the hydrophobic interactions. Nevertheless, the extent of probe-monolayer interactions, which is reflected by the magnitude of surface pressure (area) change for the compressed monolayer, is governed by charge density of both the monolayer head group region and the counter anion layer. This anionic layer is modified by the presence of DNA molecules. The number of DNA strands interacting with the monolayer is dependent on the concentration and the nature of other counter anions in a subphase (buffer, added salts). The subphase containing $10 \mathrm{mM}$ TA buffer allowed observation of the oligonucleotide effect on the DODAB monolayer compression at equimolar concentration of DNA and DODAB charges.

Figure 4 shows $\pi$-A isotherms of the DODAB monolayer recorded on the subphase containing 8.3 nM F-TBA-T or Ch(F-TBA-T) probes (Figure 4A) and py-TBA-py or Ch(py-TBA-py) probes (Figure $4 \mathrm{~B}$ ) in the absence and in the presence of potassium or sodium ions. The isotherms recorded on the F-TBA-T- or py-TBA-py-containing subphases (line 2, Figure 4A,B) are shifted into the lower surface area per molecule, when compared with the reference isotherms recorded on the subphase containing only $10 \mathrm{mM}$ TA buffer (line 1, Figure 4A,B) that indicates adsorption of DNA strands on the subphase/monolayer interface. Addition of metal cations $\left(\mathrm{K}^{+}\right.$and $\left.\mathrm{Na}^{+}\right)$that are known to promote G-quadruplex formation further affected $\pi$-A isotherms, in agreement with results reported previously for similar systems $[46,47]$. The addition of metal cations (potassium, line 3 and sodium, line 4; Figure 4A,B) further affected $\pi$-A isotherms by inducing G-quadruplex folding that resulted in a more compact monolayer formation, also in agreement with results reported previously for similar systems [46,47]. In contrast, isotherms recorded for DODAB monolayers in the presence of cholesterol-type probes (Ch(F-TBA-T) and Ch(py-TBA-py)) in the subphase (line 5, Figure 4A,B) are shifted into the higher surface area per molecule in relation to the DODAB isotherm (line 1 , Figure $4 \mathrm{~A}, \mathrm{~B})$. In this case, besides electrostatic interaction between the positively charged DODAB monolayer and the negatively charged DNA phosphates, the hydrophobic insertion of cholesterol moieties into the monolayer should be considered. The later process adds additional surface area to the DODAB film that is related to the cross-section of cholesterol moiety. The addition of potassium ions (line 6, Figure 4A,B) and sodium ions (line 7, Figure 4A,B) for cholesterol-anchors probes, induced G-quadruplex folding that resulted, similar to the probe without cholesterol (F-TBA-T, py-TBA-py), in a more compact monolayer formation compared to the monolayer for the probe in the absence of metal ions (line 5, Figure 4A,B).

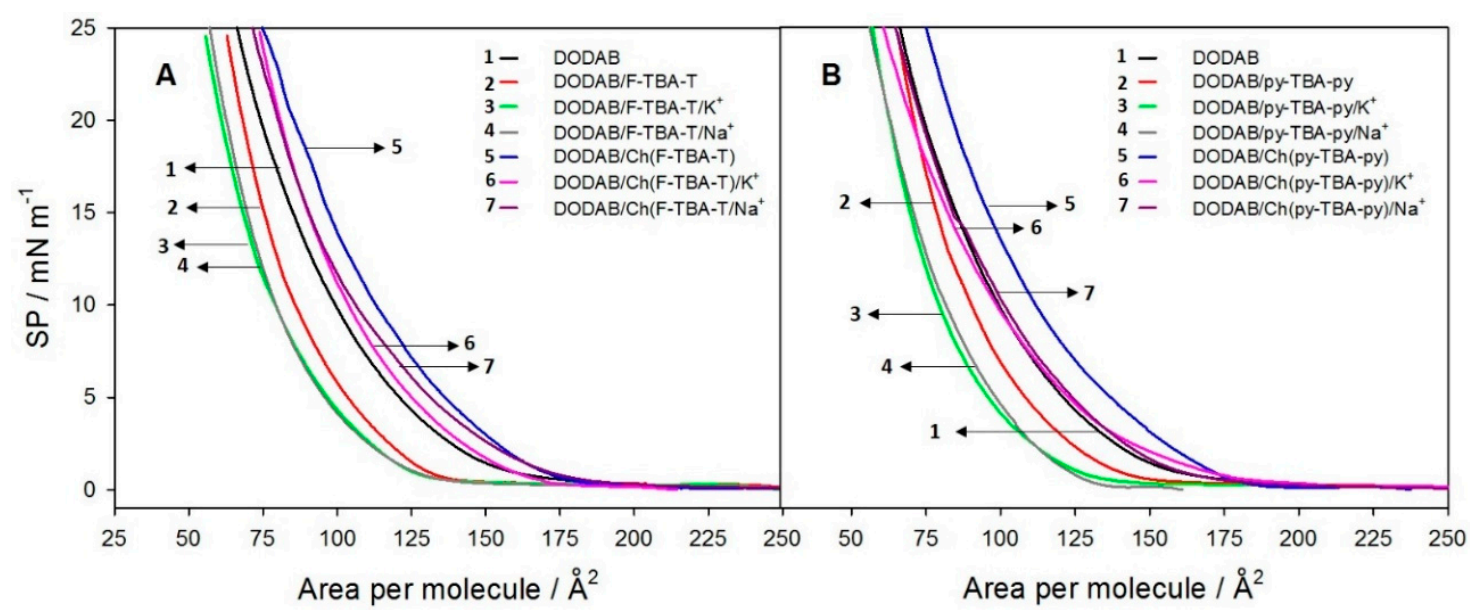

Figure 4. The $\pi$-A isotherms recorded for DODAB monolayer on a subphase containing $8.3 \mathrm{nM}$ F-TBA-T and $\mathrm{Ch}(\mathrm{F}-\mathrm{TBA}-\mathrm{T})$ probes. (A), $8.3 \mathrm{nM}$ py-TBA-py and $\mathrm{Ch}$ (py-TBA-py) probes. (B) in the absence and presence of potassium or sodium ions. Subphase contained $10 \mathrm{mM}$ TA buffer, $\mathrm{pH}=7.5$. 
Fluorescence spectra of probes were recorded with a bifurcated fiber optic accessory that was finely positioned above the monolayer surface at an angle of ca. $45^{\circ}$ and coupled to the spectrofluorimeter (Figure S1, ESI). The excitation wavelength was set at $470 \mathrm{~nm}$ for the FRET-labeled probes and at $330 \mathrm{~nm}$ for the pyrene-modified probes in order to minimize scattering at the spectral range of interest. The background scattering spectrum of the DODAB monolayer on a buffer subphase was subtracted from each spectrum of oligonucleotide probe. G-quadruplex probes dynamically adsorbed or anchored at the monolayer interface are expected to respond to the presence and the concentration of metal cations such as $\mathrm{Na}^{+}$and $\mathrm{K}^{+}$. Figure 5 shows fluorescence spectra of monolayer-anchored probes (Ch(F-TBA-T), Ch(py-TBA-py)) recorded for a relaxed and compressed monolayer, and after the addition of $\mathrm{K}^{+}$or $\mathrm{Na}^{+}$ions. Fluorescence spectra for monolayer-adsorbed probes (F-TBA-T, py-TBA-py) under the same conditions are shown in Figure S9, ESI. One can notice that the positions of fluorescence bands in the monolayer spectra are similar to those for probes in solution (Figures 1 and S3, ESI), which indicates that adsorption or anchoring of probes at the monolayer interface imposes negligible effects on the spectral properties of fluorophores. Only in the case of pyrene-modified probes (py-TBA-py, Ch(py-TBA-py)), does the monomer band at $390 \mathrm{~nm}$ not show the vibronic structure that is probably connected with stacking interactions of the pyrene fluorophore with nucleobases. The presence of the DODAB monolayer (grey line in Figure 5) does not practically affect the emission spectra of probes recorded in solution. However, compression of this relaxed monolayer to $20 \mathrm{mN} / \mathrm{m}$ (green line), caused a slight increase in intensity of fluorescence bands. The addition of potassium (red line in Figure 5) and sodium cation (blue line in Figure 5) causes analogous changes, as in the case of experiments performed in solution. Specifically, the FAM fluorescence band $(\lambda=520 \mathrm{~nm})$ is quenched, while TAMRA emission at $583 \mathrm{~nm}$ is enhanced due to FRET sensitization for Ch(F-TBA-T) (Figure 5A) and F-TBA-T (Figure S9B, ESI) probes. Similarly, the appearance of a new broad excimer band around $480 \mathrm{~nm}$, accompanied by quenching of the monomer emission $(380 \mathrm{~nm})$ is observed for Ch(py-TBA-py) (Figure 5B) and py-TBA-py (Figure S9B, ESI) probes. As expected, all probes show more efficient spectral changes for potassium ions in accordance with significantly higher binding preferences of probes to $\mathrm{K}^{+}$over $\mathrm{Na}^{+}$ions. It should be noted that the addition of metal cations behind the barriers did not exert an immediate effect on the fluorescence characteristics of the probe. The lack of fast response of the probe to the introduced cations can be rationalized in terms of a diffusion process that cannot be accelerated by, for example, stirring. However, moving the barriers backwards and re-compressing the monolayer (with adsorbed or anchored probe molecules) diminished the problem with slow diffusion of metal cation and enabled folding of the probe into G-quadruplexes. The appropriate time of equilibration ( $\sim 60 \mathrm{~min}$.) enabled effective and reproducible monitoring of spectral changes caused by the presence of cations $\left(\mathrm{K}^{+}, \mathrm{Na}^{+}\right)$.
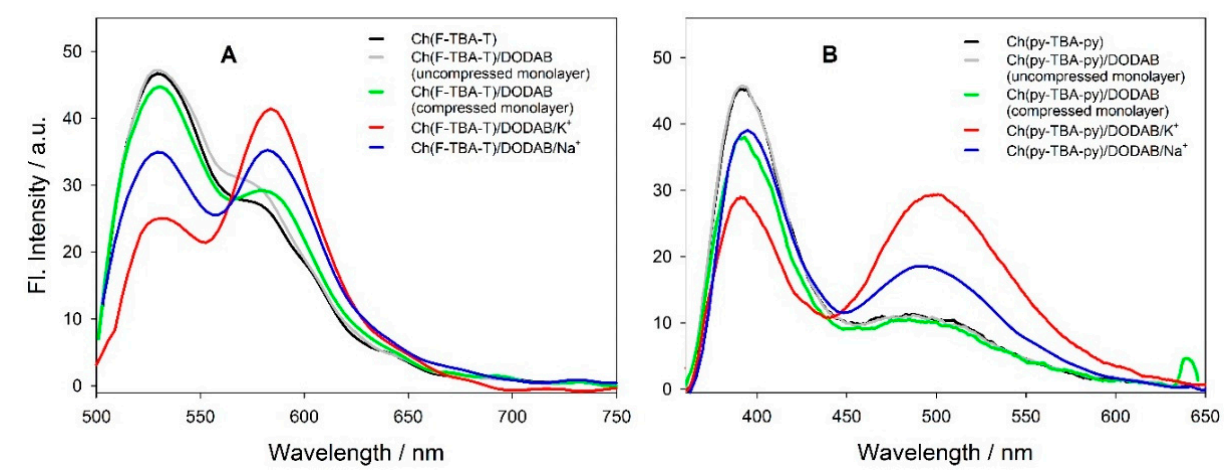

Figure 5. Emission spectra for Ch(F-TBA-T) (A) and Ch(py-TBA-py) (B) probes at monolayer DODAB interface: probe in subphase (black line), after DODAB monolayer spreading (grey line); after monolayer compression to $20 \mathrm{mN} / \mathrm{m}$ (green line); after $\mathrm{K}^{+}$addition (red line); and, after $\mathrm{Na}^{+}$ addition (blue line). Conditions: subphase contained $10 \mathrm{mM}$ TA buffer $(\mathrm{pH}=7.5)$ and $40.0 \mathrm{nM}$ probe; $100 \mathrm{mM} \mathrm{KCl}$ or $\mathrm{NaCl}$. 


\subsection{Fluorescent Bioimaging of Probes in HeLa Cells}

To visualize the successful anchoring of the $\mathrm{Ch}(\mathrm{F}-\mathrm{TBA}-\mathrm{T})$ to the outer cell membrane, we imaged the probes on the cell membrane of HeLa cells using confocal fluorescence microscopy. As shown in Figure 6A, after incubation for $0.5 \mathrm{~h}$, most of the probes are located on the cell membrane. The internalization of the $\mathrm{Ch}(\mathrm{F}-\mathrm{TBA}-\mathrm{T})$ probes was investigated by incubating cells with the probe at $37^{\circ} \mathrm{C}$ for different time intervals. Fluorescence images taken after $2 \mathrm{~h}$ (Figure 6B), $3.5 \mathrm{~h}$ (Figure S10, ESI) and $24 \mathrm{~h}$ (Figure 6C) of incubation indicated that a significant fraction of the probe was still present on the membrane of the cells; however, some of the probe molecules were clearly seen inside the cells.

(A) $0.5 \mathrm{~h}$
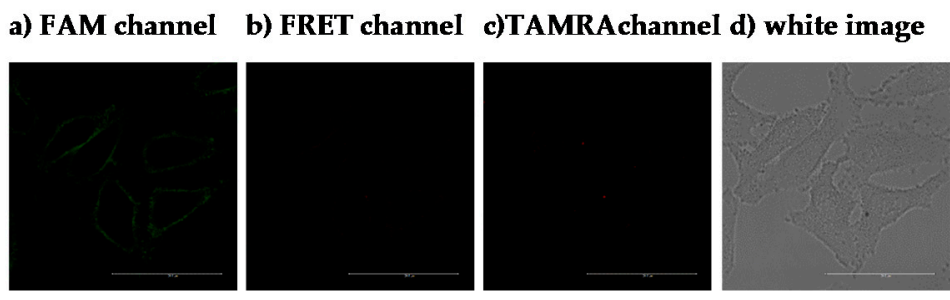

e) ovelap a)-d)

(B) $2.0 \mathrm{~h}$
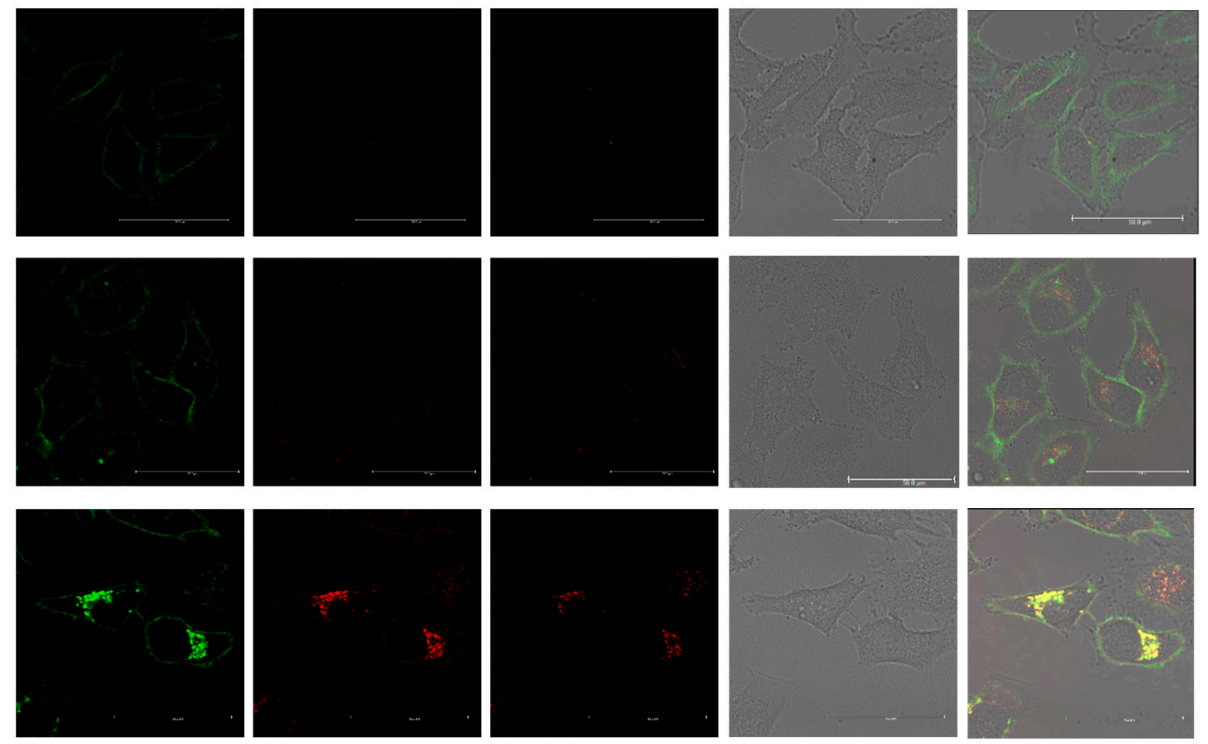

(C) overnight

Figure 6. Confocal microscopy analysis of HeLa cells treated with $50 \mathrm{nM} \mathrm{Ch(F-TBA-T)}$ for $0.5 \mathrm{~h}$ (A), $2 \mathrm{~h}$ (B) and overnight (C). Fluorescence emission filters: (1) for FAM channel (green), 510-540 nm, excitation wavelength: $480 \mathrm{~nm}$; (2) for TAMRA channel (red), 595-630 nm, excitation wavelength: $560 \mathrm{~nm}$; and, (3) for FRET channel, 595-630 nm, excitation wavelength: $480 \mathrm{~nm}$. Scale bars: $50 \mu \mathrm{m}$.

In order to determine whether the internalized $\mathrm{Ch}(\mathrm{F}-\mathrm{TBA}-\mathrm{T})$ molecules are accumulated in the nucleus, we performed an additional experiment with Hoechst 33342. Hoechst is a popular cell-permeant nuclear counterstain that emits blue fluorescence when bound to dsDNA (Figure 7B) [48]. Therefore, we added Hoechst into cells loaded previously with $\mathrm{Ch}(\mathrm{F}-\mathrm{TBA}-\mathrm{T})$. Co-localization images between $\mathrm{Ch}(\mathrm{F}-\mathrm{TBA}-\mathrm{T})$ probes and Hoechst clearly indicate that $\mathrm{Ch}(\mathrm{F}-\mathrm{TBA}-\mathrm{T})$ are not located in the nucleus (Figure 7A). Moreover, the ability of $\mathrm{Ch}(\mathrm{F}-\mathrm{TBA}-\mathrm{T})$ to enter the cells can be attributed to the presence of cholesterol moiety as the analogous probe without cholesterol moiety (F-TBA-T) was not only unable to anchor to the cell membrane, but also did not penetrate inside the cell (compare Figure 7A with Figure S10B, ESI). In the case of Ch(py-TBA-py), the situation seems to be a little more complicated as we were not able to observe fluorescence signal from the membrane bound probe but only from the probe located inside the cells (Figure S11, ESI). These results suggest the Ch(py-TBA-py) probe was able to cross the membrane due to presence of the cholesterol moiety. On the other hand, the $\mathrm{Ch}$ (py-TBA-py) probe has been previously shown to anchor into the DODAB monolayer; thus, a lack of fluorescence signal from the cell membrane bound probe may indicate both quenching by membrane constituents (e.g., proteins) or high membrane permeability of the probe enhanced by the presence of hydrophobic pyrene tags. For further evaluation of the potential applications of the $\mathrm{Ch}(\mathrm{F}-\mathrm{TBA}-\mathrm{T})$ as a potassium ion indicator, we are planning to perform experiments in cellulo with drugs able to change the potassium level. 
(A)

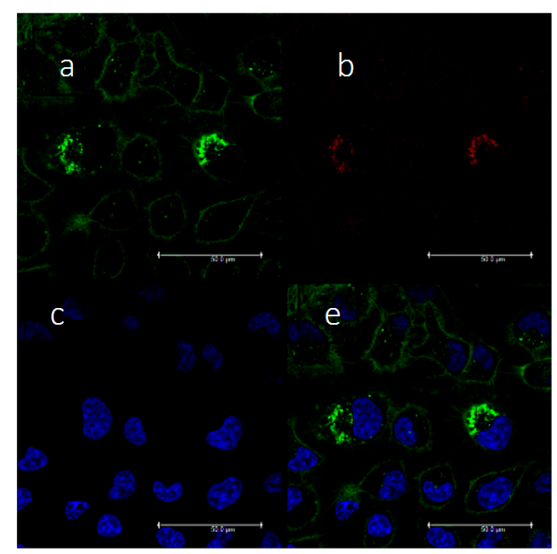

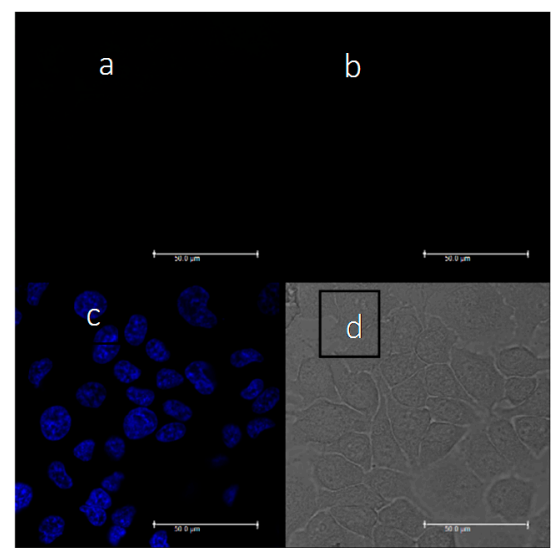

(B)

Figure 7. Confocal microscopy analysis of HeLa cells treated with $200 \mathrm{nM} \mathrm{Ch}(\mathrm{F}-\mathrm{TBA}-\mathrm{T})$ (panel (A)) and untreated (negative control in panel (B)): (a) FAM channel (green); (b) FRET channel; (c) Hoechst 33342 fluorescence form stained nuclei (blue); as well as (d) bright field image of control and (e) overlay of all images a-c of Ch(F-TBA-T). The experiment details: The probe was added at $200 \mathrm{nM}$ concentration to medium. After leaving overnight, Hoechest 33342 was applied to cell culture at a final concentration of $5 \mu \mathrm{g} / \mathrm{mL}$ and images was were taken after $15 \mathrm{~min}$. of staining. Before fluorescence imaging, experiment cells were washed twice with PBS and placed in FluoroBright Live Cell Fluorescence Imaging Medium. Fluorescence emission filters: (1) for FAM channel, 510-540 nm, excitation wavelength: $480 \mathrm{~nm}$; (2) for Hoechst channel, 480-500 nm, excitation wavelength: $405 \mathrm{~nm}$; and (3), for FRET channel, 595-630 nm, excitation wavelength: $480 \mathrm{~nm}$. Scale bars: $50 \mu \mathrm{m}$.

\section{Conclusions}

Two cholesterol-bearing fluorescent potassium probes (Ch(F-TBA-T), Ch(py-TBA-py)) based on G-quadruplexes, for spontaneous anchoring into the hydrophobic interior of lipid structures, were designed. The oligonucleotide probes preserved their abilities to fold into a G-quadruplex structure and to interact with metal cations with binding affinity and selectivity comparable to unmodified oligonucleotides. All probes exhibited higher potassium ion binding affinity and advantageous $\mathrm{K}^{+} / \mathrm{Na}^{+}$selectivity.

We also reported the G-quadruplex folding ability of cholesterol-anchored fluorescent oligonucleotide probes at the Langmuir monolayer interface, which mimicked the biomembrane surface. The monolayer (cell surface) interaction with the probe is dictated by the physicochemical properties of the probe and the monolayer (cell) interface. In our study, there were two major driving forces involved in the monolayer/probe interaction: (i) the hydrophobic insertion of cholesterol moieties into the membrane; and (ii), the electrostatic interaction between the positively charged DODAB monolayer and the negatively charged DNA. The fluorescent probes without cholesteryl-TEG anchors (F-TBA-T, py-TBA-py) appeared to bind membranes with positive charge (i.e., DODAB), which is expected for the negatively charged polyelectrolytes like DNA. On the other hand, the cholesterol-anchored probes (Ch(F-TBA-T), Ch(py-TBA-py)) penetrated the hydrophobic domain of the lipid monolayer. Based on confocal fluorescence microscopy, the cholesterol-containing fluorescent oligonucleotide probes (Ch(F-TBA-T), $\mathrm{Ch}(\mathrm{py}-\mathrm{TBA}-\mathrm{py})$ ) were shown to be located on the cell membrane of HeLa cells.

Supplementary Materials: Supplementary materials are available online at http:/ /www.mdpi.com/1424-8220/ $18 / 7 / 2201 /$ s1.

Author Contributions: A.Ś. and B.J. conceived and designed the study. A.Ś. carried out the spectral characterization of probes in bulk solution and at the air/water interface. A.S. and B.J. analyzed the data. A.D. and A.F.W. performed the fluorescent bioimaging experiments in HeLa cells, and analyzed the data. A.Ś. drafted the manuscript, which was revised and edited by A.D. and B.J. All authors read, commented on, and approved the final version of the manuscript. 
Funding: This research was financed by the National Science Centre of Poland, Grant No. 2015/19/N/ST4/00407.

Acknowledgments: Experiments using confocal microscopy were performed in the Laboratory of Subcellular Structures Analyzes at the Institute of Bioorganic Chemistry of the Polish Academy of Sciences, Poznan. The authors thank E. Kierzek for providing HeLa cells and Paula Michalak for culturing cells.

Conflicts of Interest: The authors declare no conflict of interest. The founding sponsors had no role in the design of the study; in the collection, analyses or interpretation of data; in the writing of the manuscript; nor in the decision to publish the results.

\section{References}

1. Yeagle, P.L. Cholesterol and the cell membrane. Biochim. Biophys. Acta 1985, 822, 267-287. [CrossRef]

2. Maxfield, F.R.; Tabas, I. Role of cholesterol and lipid organization in disease. Nature 2005, 438, 612-621. [CrossRef] [PubMed]

3. Letsinger, R.L.; Zhang, G.; Sun, D.K.; Ikeuchi, T.; Sarin, P.S. Cholesteryl-conjugated oligonucleotides: Synthesis, properties, and activity as inhibitors of replication of human immunodeficiency virus in cell culture. Proc. Natl. Acad. Sci. USA 1989, 86, 6553-6556. [CrossRef] [PubMed]

4. Farooqui, F.; Sarin, P.S.; Sun, D.; Letsinger, R.L. Effect of structural variations in cholesteryl-conjugated oligonucleotides on inhibitory activity toward HIV-1. Bioconjug. Chem. 1991, 2, 422-426. [CrossRef] [PubMed]

5. Krieg, A.M.; Tonkinson, J.; Matson, S.; Zhao, Q.; Saxon, M.; Zhang, L.M.; Bhanja, U.; Yakubov, L.; Stein, C.A. Modification of antisense phosphodiester oligodeoxynucleotides by a $5^{\prime}$ cholesteryl moiety increases cellular association and improves efficacy. Proc. Natl. Acid. Sci. USA 1993, 90, 1048-1052. [CrossRef]

6. Raouane, M.; Desmaële, D.; Urbinati, G.; Massaad-Massade, L.; Couvreur, P. Lipid Conjugated Oligonucleotides: A Useful Strategy for Delivery. Bioconjug. Chem. 2012, 23, 1091-1104. [CrossRef] [PubMed]

7. Chan, Y.-H.M.; van Lengerich, B.; Boxer, S.G. Effects of linker sequences on vesicle fusion mediated by lipid-anchored DNA oligonucleotides. Proc. Natl. Acad. Sci. USA 2009, 106, 979-984. [CrossRef] [PubMed]

8. Dentinger, P.M.; Simmons, B.A.; Cruz, E.; Sprague, M. DNA-mediated delivery of lipophilic molecules via hybridization to DNA-based vesicular aggregates. Langmuir 2006, 22, 2935-2937. [CrossRef] [PubMed]

9. Gissot, A.; Camplo, M.; Grinstaff, M.W.; Barthelemy, P. Nucleoside, nucleotide and oligonucleotide based amphiphiles: A successful marriage of nucleic acids with lipids. Org. Biomol. Chem. 2008, 6, 1324-1333. [CrossRef] [PubMed]

10. You, M.; Lyu, Y.; Han, D.; Qiu, L.; Liu, Q.; Chen, T.; Sam Wu, C.; Peng, L.; Zhang, L.; Bao, G.; et al. DNA probes for monitoring dynamic and transient molecular encounters on live cell membranes. Nat. Nanotechnol. 2017, 12, 453-459. [CrossRef] [PubMed]

11. Wang, H.-Y.; Hua, X.-W.; Jia, H.-R.; Liu, P.D.; Gu, N.; Chen, Z.; Wu, F.-G. Enhanced cell membrane enrichment and subsequent cellular internalization of quantum dots via cell surface engineering: Illuminating plasma membranes with quantum dots. J. Mater. Chem. B 2016, 4, 834-843. [CrossRef]

12. Gao, W.W.; Zhang, L.F. Coating nanoparticles with cell membranes for targeted drug delivery. J. Drug Target. 2015, 23, 619-626. [CrossRef] [PubMed]

13. He, H.; Bai, Y.G.; Wang, J.H.; Deng, Q.R.; Zhu, L.P.; Meng, F.H.; Zhong, Z.Y.; Yin, L.C. Reversibly cross-linked polyplexes enable cancer-targeted gene delivery via self-promoted dna release and self-diminished toxicity. Biomacromolecules 2015, 16, 1390-1400. [CrossRef] [PubMed]

14. Biffi, G.; Tannahill, D.; McCafferty, J.; Balasubramanian, S. Quantitative visualization of DNA G-quadruplex structures in human cells. Nat. Chem. 2013, 5, 182-186. [CrossRef] [PubMed]

15. Zhu, H.; Lewis, F.D. Pyrene excimer fluorescence as a probe for parallel G-quadruplex formation. Bioconjug. Chem. 2017, 18, 1213-1217. [CrossRef] [PubMed]

16. Kong, D.M.; Ma, Y.E.; Guo, J.H.; Yang, W.; Shen, H.X. Fluorescent sensor for monitoring structural changes of G-quadruplexes and detection of potassium ion. Anal. Chem. 2009, 81, 2678-2684. [CrossRef] [PubMed]

17. Li, T.; Wang, E.; Dong, S. G-Quadruplex-based DNAzyme as a sensing platform for ultrasensitive colorimetric potassium detection. Chem. Commun. 2009, 5, 580-582. [CrossRef] [PubMed]

18. Tietz, N.W. Fundamentals of Clinical Chemistry; W.B. Saunders Company: Philadephia, PA, USA, 1976; pp. 875-877. 
19. Nagatoishi, S.; Nojima, T.; Juskowiak, B.; Takenaka, S. A Pyrene-labeled G-quadruplex oligonucleotide as a fluorescence probe for potassium ions detection in biological applications. Angew. Chem. 2005, 44, 5067-5070. [CrossRef] [PubMed]

20. Nagatoishi, S.; Nojima, T.; Galezowska, E.; Gluszynska, A.; Juskowiak, B.; Takenaka, S. Fluorescence energy transfer probes based on the guanine quadruplex formation for the fluorometric detection of potassium ion. Anal. Chim. Acta 2007, 581, 125-131. [CrossRef] [PubMed]

21. Nagatoishi, S.; Nojima, T.; Galezowska, E.; Juskowiak, B.; Takenaka, S. G-quadruplex-based FRET probes with the thrombin-binding aptamer (TBA) sequence designed for the efficient fluorometric detection of the potassium ion. ChemBioChem 2006, 7, 1730-1737. [CrossRef] [PubMed]

22. He, F.; Tang, Y.; Wang, S.; Li, Y.; Zhu, D. Fluorescent amplifying recognition for DNA G-Quadruplex folding with a cationic conjugated polymer: A platform for homogeneous potassium detection. J. Am. Chem. Soc. 2005, 127, 12343-12346. [CrossRef] [PubMed]

23. Kong, D.-M.; Guo, J.-H.; Yang, W.; Ma, Y.-E.; Shen, H.-X. Crystal violet-G-quadruplex complexes as fluorescent sensors for homogeneous detection of potassium ion. Biosens. Bioelectron. 2009, 25, 88-93. [CrossRef] [PubMed]

24. Świtalska, A.; Juskowiak, B. Effect of Cholesterol Anchoring Group on the Properties of G-Quadruplex-Based FRET Probes for Potassium Ion. Chemosensors 2014, 2, 267-286. [CrossRef]

25. Vance, D.E.; Vance, J.E. Biochemistry of Lipids, Lipoproteins and Membranes, 4th ed.; Elsevier: New York, NY, USA, 2006; ISBN 9780080930169, 9780080574813.

26. Bock, L.C.; Griffin, L.C.; Latham, J.A.; Vermaas, E.H.; Toole, J.J. Selection of single-stranded DNA molecules that bind and inhibit human thrombin. Nature 1992, 355, 564-566. [CrossRef] [PubMed]

27. Mergny, J.L.; Phan, A.T.; Lacroix, L. Following G-quartet formation by UV-spectroscopy. FEBS Lett. 1998, 435, 74-78. [CrossRef]

28. Kumke, M.U.; Li, G.; McGown, L.B.; Walker, G.T.; Linn, C.P. Hybridization of fluorescein-labeled DNA oligomers detected by fluorescence anisotropy with protein binding enhancement. Anal. Chem. 1995, 67, 3945-3951. [CrossRef] [PubMed]

29. Fasman, G.D. Handbook of Biochemistry and Molecular Biology, Nucleic Acids, 3rd ed.; CRC Press: Cleaveland, OH, USA, 1975; p. 589; ISBN 9780849391682.

30. Viglasky, V.; Bauer, L.; Tluckova, K. Structural features of intra-and intermolecular G-quadruplexes derived from telomeric repeats. Biochemistry 2010, 49, 2110-2120. [CrossRef] [PubMed]

31. Clegg, R.M. Fluorescence resonance energy transfer and nucleic acids. Methods Enzymol. 1992, 211, 353-388. [CrossRef] [PubMed]

32. Lakowicz, J.R. Principles of Fluorescence Spectroscopy, 3rd ed.; Springer: New York, NY, USA, 2006; pp. 443-453; ISBN 978-0-387-46312-4.

33. Winnik, F.M. Photophysics of preassociated pyrenes in aqueous polymer solutions and in other organized media. Chem. Rev. 1993, 93, 587-614. [CrossRef]

34. Duhamel, J. New insights in the study of pyrene excimer fluorescence to characterize macromolecules and their supramolecular assemblies in solution. Langmuir 2012, 28, 6527-6538. [CrossRef] [PubMed]

35. Venner, H. Molekülverbindungen einiger Sterine und Sterinester mit Nitroaromaten. Chem. Ber. 1956, 89, 1634-1641. [CrossRef]

36. Pagano, B.; Martino, L.; Randazzo, A.; Giancola, C. Stability and binding properties of a modified thrombin binding aptamer. Biophys. J. 2008, 94, 562-569. [CrossRef] [PubMed]

37. Nagatoishi, S.; Isono, N.; Tsumoto, K.; Sugimoto, N. Loop residues of thrombin-binding DNA aptamer impact G-quadruplex stability and thrombin binding. Biochimie 2011, 93, 1231-1238. [CrossRef] [PubMed]

38. Mergny, J.L.; Maurizot, J.C. Fluorescence resonance energy transfer as a probe for G-quartet formation by a telomeric repeat. ChemBioChem 2001, 2, 124-132. [CrossRef]

39. Swiatkowska, A.; Kosman, J.; Juskowiak, B. FRET study of G-quadruplex forming fluorescent oligonucleotide probes at the lipid monolayer interface. Spectrochim. Acta A 2016, 152, 614-621. [CrossRef] [PubMed]

40. Schultze, P.; Macaya, R.F.; Feigon, J. Three-dimensional solution structure of the thrombin-binding DNA aptamer d(GGTTGGTGTGGTTGG). J. Mol. Biol. 1994, 235, 1532-1547. [CrossRef] [PubMed]

41. Kankia, B.I.; Marky, L.A. Folding of the thrombin aptamer into a G-quadruplex with $\mathrm{Sr}^{2+}$ : Stability, heat, and hydration. J. Am. Chem. Soc. 2001, 123, 10799-10804. [CrossRef] [PubMed] 
42. Sastry, M.; Ramakrishnan, V.; Pattarkine, M.; Gole, A.; Ganesh, K.N. Hybridization of DNA by sequential immobilization of oligonucleotides at the air-water interface. Langmuir 2000, 16, 9142-9146. [CrossRef]

43. Ramakrishnan, V.; D'Costa, M.; Ganesh, K.N.; Sastry, M. Effect of salt on the hybridization of DNA by sequential immobilization of oligonucleotides at the air-water interface in the presence of ODA/DOTAP monolayers. J. Colloid Interface Sci. 2004, 276, 77-84. [CrossRef] [PubMed]

44. Cardenas, M.; Nylander, T.; Joensson, B.; Lindman, B. The interaction between DNA and cationic lipid films at the air-water interface. J. Colloid Interface Sci. 2005, 286, 166-175. [CrossRef] [PubMed]

45. Chatterji, D.; Rajdev, P. Macromolecular recognition at the air-water interface: Application of Langmuir-Blodgett technique. Curr. Sci. 2008, 95, 1226-1236.

46. Juskowiak, B.; Paczesny, J. The interaction between G-quadruplex-forming oligonucleotide and cationic surfactant monolayer at the air/water interface. J. Colloid Interface Sci. 2012, 365, 150-155. [CrossRef] [PubMed]

47. Juskowiak, B.; Swiatkowska, A. Study of the G-quadruplex-dipalmitoylphosphatidylcholine interactions at the air/water interface. Colloids Surf. A Physicochem. Eng. Asp. 2013, 417, 250-255. [CrossRef]

48. Johnson, I.; Spence, M. Molecular Probes Handbook: A Guide to Fluorescent Probes and Labeling Technologies, 11st ed.; Life Technologies: Carlsbad, CA, USA, 2010; p. 319; ISBN 0982927916, 978-0982927915.

(C) 2018 by the authors. Licensee MDPI, Basel, Switzerland. This article is an open access article distributed under the terms and conditions of the Creative Commons Attribution (CC BY) license (http://creativecommons.org/licenses/by/4.0/). 